VIII.-The Action of Sulphuric Acid on Copper. By (the late) James Tudor Cundald (with appendix by Mungo McCallum Fairgrieve).

Some time ago, in order to demonstrate the formation of copper sulphide in the preparation of sulphur dioxide by the action of concentrated sulphuric acid on copper turnings, I poured the dark liquid obtained into a large quantity of water, when I was surprised 
to find that a bright red precipitate was produced instead of a black one.

A number of experiments were then made, in which different samples of copper were heated under varying conditions with sulphuric acid in order to investigate the nature of this precipitate. It was found at first that the formation of the red precipitate was apparently capricious, variations in the sample of copper, and of sulphuric acid, in the time of action, and in the temperature having no constant effect; but in general it was noticed that the brightest red precipitates were usually obtained when the copper and sulphuric acid were heated until a brisk action occurred, the flame then removed, and the liquid allowed to remain a little before being poured off. The necessary delay was shorter the more finely divided the copper. In order to avoid contaminating the precipitate with copper sulphide or particles of copper carried over mechanically in the liquid, the latter was filtered through asbestos in a Gooch crucible into the water.

It was then found that not only was the red precipitate formed when a sample of copper was acted on by successive quantities of acid, but also if portions of the liquid were drawn off at all stages of the action until the copper was nearly all dissolved.

The red precipitate was formed most strikingly when the filtrate, although clear, was of a reddish-brown colour, and only appeared as the liquid diffused into the water. It was extremely finely divided, only settling after some hours. When collected and washed on a Gooch filter it assumed a metallic appearance, forming bright films of a coppery lustre that floated in the crucible. The weights of the precipitate were small, and could not be materially increased by increasing the amount of the acting substances or the time of action. They varied from 0.03 to 0.22 gram in weight, and were quite similar whether commercial copper turnings, "pure precipitated copper," finely divided copper obtained by reducing pure copper oxide in hydrogen, or very pure electrolytic foil free from arsenic were used.

The precipitates were then analysed, 0.135 gram yielding 0.135 gram of copper, and 0.223 gram yielding 0.220 gram of copper. They were therefore practically pure copper. Other samples were examined for sulphur by conversion into barium sulphate, yielding only $0.24,0.16$, and 0.03 per cent.

The red precipitate being therefore metallic copper, is formed in all probability by the decomposition of cuprous sulphate by water, as shown by Recoura (Compt. rend., 1909, 148, 1105):

$$
\mathrm{Cu}_{2} \mathrm{SO}_{4}=\mathrm{CuSO}_{4}+\mathrm{Cu}
$$

and a sample of cuprous sulphate prepared by Recoura's method 
gave with water a red precipitate identical in appearance with that obtained by the process described above.

Suspicion having been aroused that the concentration of the sulphuric acid was the condition deciding the formation of the red precipitate, a series of experiments was made, in which sulphuric acid of various strengths was made to act on pure copper foil. If "pure distilled sulphuric acid" ( $\left.\mathrm{D}^{15} 1.8399\right)$ containing approximately $95 \cdot 4$ per cent. of $\mathrm{H}_{2} \mathrm{SO}_{4}$ was used, the red precipitate could not be obtained, and it was only on diluting it until the percentage of $\mathrm{H}_{2} \mathrm{SO}_{4}$ was reduced to about 94 that it definitely appeared, becoming well marked at 91 per cent., and perhaps at its best at about 87 per cent. At lower percentages red precipitates were produced, but the action of the acid on the copper only continued of itself if the mixture was heated repeatedly.

On examining the course of the action in the various cases it was seen that the reddish-brown liquid mentioned above as giving the red precipitate best when poured on to water was always to be noticed as pouring off the copper, but whereas in the weaker acids it persisted, in the more concentrated it rapidly became dark greenish as it passed away from the neighbourhood of the copper.

If the reddish-brown liquid is allowed to remain or is gently heated it darkens and deposits a greyish-black precipitate. This precipitate when collected and washed resembles cuprous sulphide, and a portion weighing 0.0210 gram gave 0.0158 gram or 75 per cent. of copper $\left(\mathrm{Cu}_{2} \mathrm{~S}=: 79.9\right.$ per cent. $\mathrm{Cu}$ and $\mathrm{CuS}=66.5$ per cent. $\mathrm{Cu}$. It thus approximates to cuprous sulphide.

When more strongly heated the reddish-brown liquid becomes greenish-black, and deposits a greenish-black precipitate, of which 0.318 gram gave 0.2114 gram (=66.5 per cent.) of copper, and was therefore pure cupric sulphide, although if the heating is continued the precipitate dissolves with evolution of sulphur dioxide:

$$
\mathrm{CuS}+4 \mathrm{H}_{2} \mathrm{SO}_{4}=\mathrm{CuSO}_{4}+4 \mathrm{SO}_{2}+4 \mathrm{H}_{2} \mathrm{O} \text {. }
$$

The final result of the reaction, if carried as far as possible, results in the maximum production of sulphur dioxide, as indicated by the equation:

$$
\mathrm{Cu}+2 \mathrm{H}_{2} \mathrm{SO}_{4}=\mathrm{CuSO}_{4}+\mathrm{SO}_{2}+2 \mathrm{H}_{2} \mathrm{O}
$$

showing a ratio of copper dissolved to sulphur dioxide set free of 1 to 1 (which may be observed by seeing that no solid residue is obtained).

If the cupric sulphide is left unacted on, the ratio of copper to sulphur dioxide rises to $3: 1$, and the ratio of copper as copper sulphate to copper as sulphide becomes $5 \cdot 7: 1$, a relation which may be expressed by the formula:

$$
6 \mathrm{Cu}+8 \mathrm{H}_{2} \mathrm{SO}_{4}=5 \mathrm{CuSO}_{4}+\mathrm{CuS}+2 \mathrm{SO}_{2}+8 \mathrm{H}_{2} \mathrm{O} \text {. . }
$$


If plenty of copper is left unacted on, cuprous sulphide is obtained, and the ratio of copper used to sulphur dioxide produced rises to $6: 1$, the equation for this being:

$$
6 \mathrm{Cu}+6 \mathrm{H}_{2} \mathrm{SO}_{4}=\mathrm{CuSO}_{4}+\mathrm{Cu}_{2} \mathrm{~S}+\mathrm{SO}_{2}+6 \mathrm{H}_{2} \mathrm{O} \text {. . }
$$

\section{Note on Above.}

The late Mr. Cundall left the draft of his research thus incomplete, but from an earlier manuscript and from conversation with him I gather that he might have completed it and summarised his results somewhat as follows:

The primary reactions of copper and sulphuric acid may be represented by the following equations :

(a) $8 \mathrm{Cu}+4 \mathrm{H}_{2} \mathrm{SO}_{4}=3 \mathrm{Cu}_{2} \mathrm{SO}_{4}+\mathrm{Cu}_{2} \mathrm{~S}+4 \mathrm{H}_{2} \mathrm{O}$,

(b) $2 \mathrm{Cu}+2 \mathrm{H}_{2} \mathrm{SO}_{4}=\mathrm{Cu}_{2} \mathrm{SO}_{4}+2 \mathrm{H}_{2} \mathrm{O}+\mathrm{SO}_{2}$, whilst the secondary reactions of the products formed are:

(c) $5 \mathrm{Cu}_{2} \mathrm{SO}_{4}+4 \mathrm{H}_{2} \mathrm{SO}_{4}=\mathrm{Cu}_{2} \mathrm{~S}+8 \mathrm{CuSO}_{4}+4 \mathrm{H}_{2} \mathrm{O}$,

(d) $\mathrm{Cu}_{2} \mathrm{~S}+2 \mathrm{H}_{2} \mathrm{SO}_{4}=\mathrm{CuS}+\mathrm{CuSO}_{4}+2 \mathrm{H}_{2} \mathrm{O}+\mathrm{SO}_{2}$, and

(e) $\mathrm{CuS}+4 \mathrm{H}_{2} \mathrm{SO}_{4}=\mathrm{CuSO}_{4}+4 \mathrm{SO}_{2}+4 \mathrm{H}_{2} \mathrm{O}$.

Cuprous sulphate is the primary product, both when the sulphuric acid is concentrated, and when it is diluted with water ["The reddish-brown liquid was always to be noticed as pouring off the copper," see above], although a maximum value is given when the diluted acid approximates to one containing molecular proportions of sulphuric acid and water. In hot concentrated acid, however, the cuprous sulphate is even more unstable than in the slightly diluted acid, and reacts almost at once, as indicated by equation (c).

Equation $(a)$ is apparently specially a low-temperature reaction, and it is interesting to note that if combined with $(c)$ in the proportion of $5(a)+3(c)$ we get :

$$
5 \mathrm{Cu}+4 \mathrm{H}_{2} \mathrm{SO}_{4}=\mathrm{Cu}_{2} \mathrm{~S}+3 \mathrm{CuSO}_{4}+4 \mathrm{H}_{2} \mathrm{O} \text {, }
$$

one of Pickering's fundamental reactions (T., 1878, 33, 112).

Equation (5) is made up of $a+2 b+c$, and

$$
a+2 b+c+2 d \text {. }
$$

To get the ordinary equation for the completed action (3) it is, of course, possible to use either " $a$ " or " $b$ " in combination with " $c$," " $d$, , and " $e . "$

Mr. Cundall's results, therefore, on the whole confirm the final results of Pickering, although the mechanism of the changes involved is different, inasmuch as cuprous sulphate is regarded as the primary substance formed.

Science Department,

Thr Edinburgh Academy. 